\title{
Application of linear model of sorption dynamics to the comparison of solid phase extraction systems of phenol
}

\author{
G.I. Tsysin*, I.A. Kovalev, P.N. Nesterenko, N.A. Penner, O.A. Filippov \\ Department of Chemistry, Moscow State University, Moscow 119899, Russia
}

Received 23 March 2002; received in revised form 28 September 2002; accepted 1 October 2002

\begin{abstract}
A method based on the linear model of sorption dynamics (LMSD) is applied for the comparison of several solid phase extraction systems used for preconcentration of phenol from water solutions. The method includes the calculation of maximum concentration efficiency for the given values of preconcentration factor and recovery under scope of the model. Original parameters of LMSD were obtained from the experimental data on kinetics of sorption of phenol on different hydrophobic non-polar sorbents including poly(styrene-divinylbenzene) (Amberlite XAD-2, PLPRS 100), hypercrosslinked polystyrene (Purosorb MN-200), hexadecylsilica (KSK-G C 16 ) and others (Amberlite XAD-4, Amberchrom CG-161). The suitability of LMSD for evaluation of dynamic sorption systems is discussed.

(C) 2002 Elsevier Science B.V. All rights reserved.
\end{abstract}

Keywords: Solid phase extraction; Phenol; Linear model of sorption dynamics

\section{Introduction}

Phenol and its derivatives are common reagents in many industrial processes so they are presented in different industrial and wastewaters. Being important water pollutants these compounds have to be under continuous monitoring in different types of water, even at very low concentration level. So, the European Community Directive

\footnotetext{
* Corresponding author.

E-mail address: tsisin@analyt.chem.msu.ru (G.I. Tsysin).
}

specified a legal tolerance level for each phenol to be less than $0.1 \mu \mathrm{g} 1^{-1}$ and to be less than 0.5 $\mu \mathrm{g} 1^{-1}$ for the sum of phenols in waters intended for any human consumption. In practice, the phenols are usually determined by reversed phase HPLC with UV [1,2] or electrochemical detection [3]. As it has been noted in many papers, the reliable direct determination of phenols in waters at the concentration level $0.1-0.4 \mu \mathrm{g} 1^{-1}$ is a rather difficult task. So, the preconcentration of phenols from water samples is necessary for their HPLC determination at sub-ppm level [4-11]. Solid phase extraction (SPE) is a common techni- 


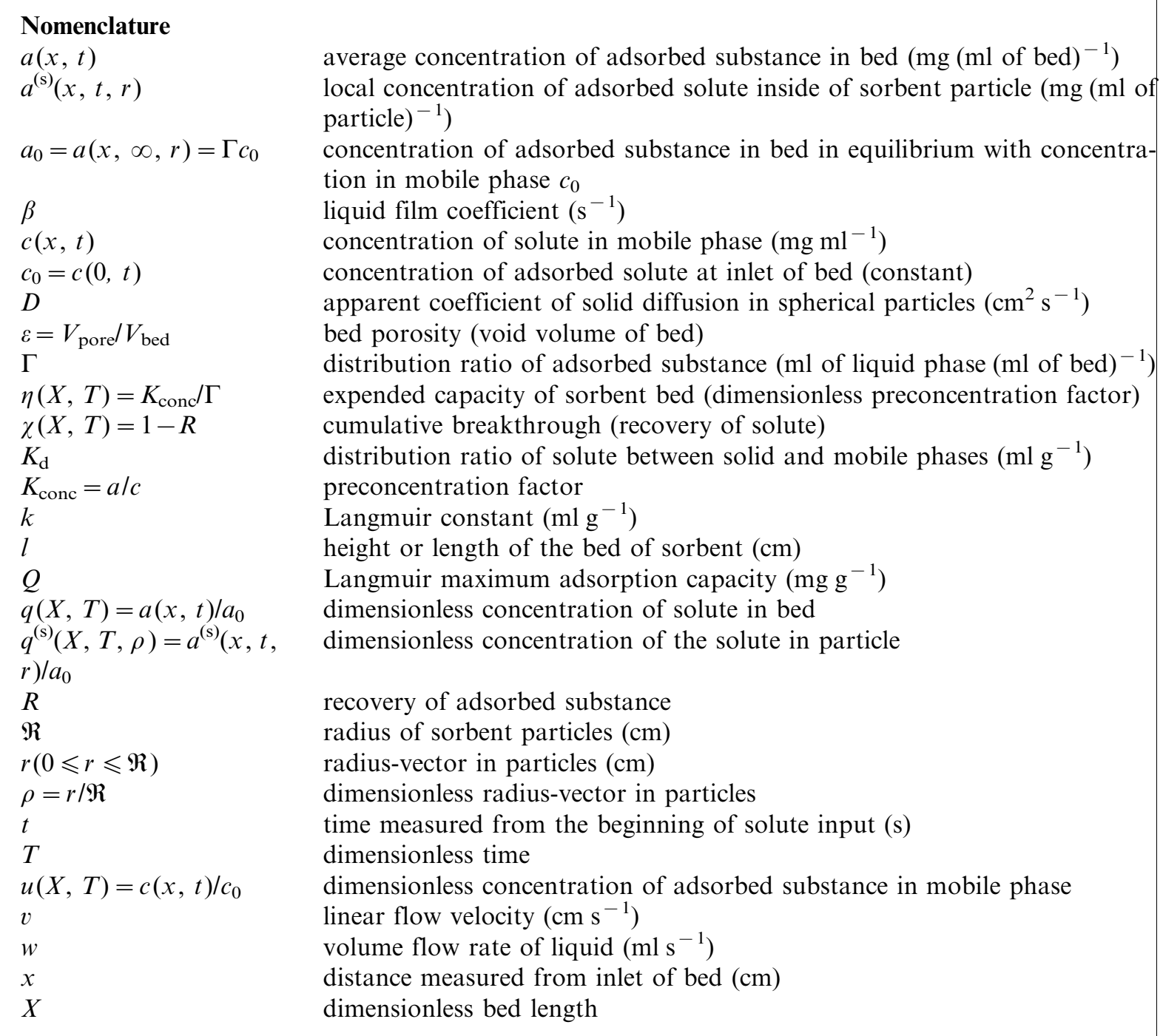

que for the preconcentration of phenols, because of its simplicity, possibility to achieve high preconcentration factors in a short time, low risk of sample contamination, and etc. The main problem of SPE of phenols is the low recovery of hydrophilic phenols, in particular of non-substituted phenol. Therefore the development of new and improvement of known types of adsorbents for the preconcentration of phenol remains an important task during almost three decades.

There are three main groups of sorbents used for the preconcentration of phenols. The first one includes chemically modified silica. The most popular in this group is octadecylsilica or ODS $[4,12]$. However, chemically modified silica exhibits rather small affinity to phenol and phenol's recovery is low [13]. The second group involves polymeric sorbents, mainly poly(styrene-divinylbenzene)s with different cross-linking degree and porous structure: XAD-2 [13,14], XAD-4 [13,1518], Bond Elut PPL [10,13], Amberchrom CG-161 [13,19], PLRP-S 100 [13,20]. Recently, a number of new materials based on hypercrosslinked polystyrene and high crosslinked poly(styrene-divinylben- 
zene) under trade names LiChrolut EN [8,13,21], Purolite Macronet Hypersol [13,22-25], Isolute ENV $[8,13]$, HYSphere-1 [10,13] and Envi-Chrom $\mathrm{P}[13,21]$ appeared. These sorbents have high cross-linking degree ( $80 \%$ and more) and their developed porous structure provides high values of specific surface area. The other feature of these sorbents is increased ability to $\pi-\pi$ interactions with aromatic substances. So, the increased recovery of phenol and its hydrophilic derivatives was noticed. The last group of sorbents includes various carbon black modifications such as Carbopack B [10], carbon fiber [9] and silica coated with porous graphitic carbon or Hypercarb [26] with special high selectivity for polar organics. The main characteristics of these sorbents are summarized in Table 1.

Taking into consideration the big variety of sorbents applied for SPE of phenol and their significantly different properties, it is important to find out suitable criteria for the scientifically justified choice of the most efficient sorbent for dynamic preconcentration of phenol. Usually, such choice is based on the measurement of distribution ratio under static conditions that is not completely correct due to ignoring of considerable role of mass-transfer rate in the recovery of solute under dynamic conditions.

A new approach to the choice of the most efficient dynamic sorption system, based on the linear model of sorption dynamics (LMSD), is proposed in present work and different sorbents are compared for the preconcentration of phenol.

\section{Theory}

There are two basic models of mass transfer which have been applied to the investigations of phenol sorption: the liquid film diffusion model, considering diffusion of the solute from the solution to the surface of adsorbent as the rate limited factor, and the solid diffusion model, where diffusion of the solute inside sorbent particle is considered as the rate limited factor [27,28]. Brief description of these models is given below.
First of all, there are a number of statements to simplify the consideration of kinetics of sorption in the fixed bed system:

- the adsorbent in a column consists of homogeneous monosize spherical particles;

- the solute containing solution flows through the column/bed with a constant velocity;

- the solution flow is considered both in sorbent bed and in mobile phase volume as in homogeneous media;

- the role of axial diffusion due to turbulence in the overall mass transfer kinetics is negligible as compared to the film and solid phase diffusion;

- the model parameters such as distribution ratio $K_{\mathrm{d}}$, liquid film coefficient $\beta$, solid phase diffusion coefficient $D$ of substance as well as geometrical and hydrodynamic parameters of system under scope are independent from the concentration of substance and its placement in total system.

These assumptions mean the system is linear and a single dimensional (there is only one variable $x$ - the bed length); time $t$ should be used for description of system too. The models are formulated to satisfy exactly to a system of differential equations and boundary conditions.

\subsection{Mass balance}

Differential mass balance can be expressed as

$$
v \frac{\partial c}{\partial x}+\varepsilon \frac{\partial c}{\partial t}+\frac{\partial a}{\partial t}=0
$$

where $c$ and $a$ are the concentrations of solute in the mobile and in the stationary phases, $v$ is the linear velocity of mobile phase and $\varepsilon$ is the porosity of the column expressed as ratio of column void volume to the total volume of sorbent bed in the column. The concentrations are expressed in mass units of solute per unit of volume of mobile phase $(c)$ or volume of stationary phase (a). 
Table 1

The main characteristics of sorbents used for phenol preconcentration $[13,19-21]$

\begin{tabular}{|c|c|c|c|c|c|c|c|}
\hline Sorbent & Manufacturer & $\begin{array}{l}\text { Matrix } \\
\text { nature }\end{array}$ & $\begin{array}{l}\text { Cross-linking } \\
\text { degree, } \%\end{array}$ & $\begin{array}{l}\text { Specific surface area } S, \\
\mathrm{~m}^{2} \mathrm{~g}^{-1}\end{array}$ & $\begin{array}{l}\text { Pore diameter, } \\
\AA\end{array}$ & $\begin{array}{l}K_{\mathrm{d}} \text { (phenol), } \\
\mathrm{ml} \mathrm{g}^{-1}\end{array}$ & $\begin{array}{l}\text { Adsorption capacity of phenol, } \\
\mathrm{mg} \mathrm{g}^{-1}\end{array}$ \\
\hline KSK-G C 16 & BioChemMack & Silica- $\mathrm{C}_{16}$ & - & 250 & - & 1.7 & 1.2 \\
\hline $\begin{array}{l}\text { Merrifield poly- } \\
\text { styrene }\end{array}$ & Reanal & Ps-dvb ${ }^{\mathrm{a}}$ & 2 & - & - & 3.2 & 0.4 \\
\hline Amberlite XAD-2 & Serva & Ps-dvb ${ }^{a}$ & 8 & 300 & 90 & 79 & 0.7 \\
\hline Amberlite XAD-4 & Serva & Ps-dvb ${ }^{a}$ & 16 & 750 & 50 & 270 & 1.1 \\
\hline PLRP-S 100 & Polymer Labs & Ps-dvb ${ }^{a}$ & 60 & 500 & 100 & - & 2.1 \\
\hline $\begin{array}{l}\text { Amberchrom CG- } \\
161\end{array}$ & TosoHaas & Ps-dvb ${ }^{a}$ & - & 900 & 150 & - & 4.6 \\
\hline Envi-Chrom P & Supelco & Ps-dvb hcd ${ }^{\mathrm{b}}$ & 100 & $800-950$ & $110-175$ & - & 4.2 \\
\hline LiChrolut EN & Merck & Ps-dvb hed & 100 & 1200 & - & - & 18 \\
\hline $\mathrm{MN}-100$ & Purolite Int. & $\mathrm{Hcps}^{\mathrm{c}}$ & $>100$ & 1500 & $1000(15)$ & 843 & 9.4 \\
\hline MN-150 & Purolite Int. & Hcps & $>100$ & 1070 & $300(14)$ & 759 & 36 \\
\hline Purosorb MN-200 & Purolite Int. & Hcps & $>100$ & 1500 & $1000(11)$ & 636 & 36 \\
\hline
\end{tabular}

${ }^{a}$ Ps-dvb - polystyrene-divinylbenzene.

b Ps-dvb hod - polystyrene-divinylbenzene with high cross-linking degree.

c Hcps-hyper cross-linked polystyrene. 


\subsection{Mass transfer kinetics}

Concerning liquid film diffusion model, the mass transfer rate can be expressed by the following equation:

$\frac{\partial a}{\partial t}=\beta\left(c-f_{-1}(a)\right)$

where $\beta$ is the liquid film coefficient and $f_{-1}(a)$ is the reciprocal function of the adsorption isotherm of solute.

The solid phase diffusion model supposes the diffusion inside sorbent particles as the rate-limiting step. So, the mass transfer can be expressed as

$\frac{\partial a^{(\mathrm{s})}}{\partial t}=\frac{1}{r^{2}} \frac{\partial}{\partial r}\left(r^{2} D \frac{\partial a^{(\mathrm{s})}}{\partial r}\right)$

where $a^{(\mathrm{s})}(x, t, r)$ is a local concentration of adsorbed substance inside of the sorbent particle; $D$ is its apparent solid diffusion coefficient; $r$ is the radius-vector from center of particle to its surface $(0 \leqslant r \leqslant \Re$, where $\mathfrak{R}$ is the particle radius). The relation between the local concentration $a^{(s)}(x, t$, $r$ ) of adsorbed substance and its average concentration over the volume of sorbent bed layer $a(x$, $t$ ) is expressed by the following equation:

$$
\left.a(x, t)=\frac{3}{\mathfrak{R}^{3}}(1-\varepsilon) \int_{0}^{\mathfrak{R}} a^{(\mathrm{s})}(x, t, r) r^{2} \mathrm{~d} r\right)
$$

\subsection{Equilibrium isotherm}

The adsorption isotherm is assumed to be linear (Henry type):

$a=\Gamma c$,

where $\Gamma$ is distribution ratio of the solute, calculated as ratio of its concentration in a volume of mobile phase to the concentration in a volume of stationary phase $\left(\mathrm{ml} \mathrm{ml}^{-1}\right)$.

\subsection{Initial and boundary conditions}

Initial and boundary conditions are corresponded to the column operating under conventional preconcentration mode.

For liquid film diffusion:

$$
\begin{gathered}
c(x, 0)=0_{x \neq 0} ; \quad c(0, t)= \begin{cases}0, & t=0 \\
c_{0}, & t>0\end{cases} \\
a(x, 0)=0
\end{gathered}
$$

and for solid phase diffusion:

$$
\begin{gathered}
c(x, 0)=0_{x \neq 0} ; \quad c(0, t)= \begin{cases}0, & t=0 \\
c_{0}, & t>0\end{cases} \\
a^{(\mathrm{s})}(x, 0, r)=0 ; \quad a^{(\mathrm{s})}(x, t, \mathfrak{R})=\frac{\Gamma c}{1-\varepsilon} \\
\frac{\partial a^{(\mathrm{s})}(x, t, 0)}{\partial r}=0
\end{gathered}
$$

There is no solute both in liquid and solid phases at the beginning of the experiment.

\subsection{Solutions}

The introduction of dimensionless variables allows reducing the number of independent parameters in the system of equations Eqs. (1)-(5). Hence, the solution of system Eqs. (1)-(5) can be expressed by a number of dimensionless functions:

$$
\begin{gathered}
u(X, T)=c(x, t) / c_{0} ; \quad q(X, T)=a(x, t) / \Gamma c_{0} ; \\
q^{(\mathrm{s})}(X, T, \rho)=a^{(\mathrm{s})}(x, t, r) /(1-\varepsilon) \Gamma c_{0}
\end{gathered}
$$

where $u(X, T), q(X, T)$ and $q^{(\mathrm{s})}(X, T, \rho)$ are dimensionless concentrations of the solute, expressed per unit volume of mobile phase, stationary phase and sorbent particle, correspondingly; $X, T$ and $\rho$ is a set of dimensionless variables corresponding to length $x$, time $t$ and radiusvector $r$ in the particle: $X=x / \xi, T=t / \tau, \rho=r / \mathfrak{R}$. Parameters $\xi$ and $\tau$ are the characteristic scales of length and time:

$\xi=v / \beta, \quad \tau=\Gamma / \beta \quad$ (liquid film diffusion model)

$\xi=\mathfrak{R}^{2} v / D \Gamma, \quad \tau=\mathfrak{R}^{2} / D \quad$ (solid diffusion model)

Solutions of system Eqs. (1)-(5) have been 
obtained in a form suitable for numerical integration [27-29].

\section{Experimental}

The number of sorbents including hexadecylsilica KSK-G $\mathrm{C}_{16}$ (BioChemMack, Moscow, Russia); Merrifield-type resin or chloromethylated poly(styrene-divinylbenzene) with $2 \%$ DVB (Reanal, Hungary); poly(styrene-divinylbenzene)s Amberchrom CG-161, XAD-2 and XAD-4 (all from Serva, Heidelberg, Germany); highly crosslinked poly(styrene-divinylbenzene)s Envi-Chrom P (Supelco, USA); hypercrosslinked polystyrenes $\mathrm{Li}$ Chrolut EN (Merck, Germany), Purosorb MN200, Macronet MN-100 and MN-150 series (all from Purolite Int, Pontyclun, UK) was studied in experiments on adsorption of phenol. The main characteristics of above listed sorbents are presented in Table 1.

The adsorption isotherms of phenol on hexadecylsilica, Amberlite XAD-2, XAD-4 resins, Purosorb MN-200, MN-150, MN-100 and Merrifield resin were obtained under static conditions by incubation of $0.02-0.5 \mathrm{~g}$ of sorbents with $5 \mathrm{ml}$ of phenol solution $\left(\mathrm{pH} 2.0,25{ }^{\circ} \mathrm{C}\right)$ during $24 \mathrm{~h}$. Distribution ratios of phenol $K_{\mathrm{d}}\left(\mathrm{ml} \mathrm{g}^{-1}\right)$ and $\Gamma$ $\left(\mathrm{ml} \mathrm{ml}^{-1}\right)$ were calculated per unit of mass of sorbent and volume of stationary phase, correspondingly, from the transformed Langmuir equation $\left(a^{(\mathrm{s})}=Q k c /(1+k c)\right.$, where $Q$ is the maximum adsorption capacity, $\mathrm{mg} \mathrm{g}^{-1}$ and $k$ is the Langmuir constant, $\mathrm{ml} \mathrm{mg}^{-1}$ ) as follows:

$K_{\mathrm{d}}=a^{(\mathrm{s})} / c ; \quad \Gamma=(1-\varepsilon) K_{\mathrm{d}}$

The concentration of phenol in solutions was determined by reversed-phase HPLC with photometric detection.

The kinetics of phenol adsorption was studied by the method of dynamic breakthrough curves [29]. Kinetic experiments under dynamic conditions were performed with isocratic liquid chromatograph consisted of high-pressure pump Beckman 114 M (Palo Alto, USA) and spectrophotometric detector microUVIS 20 (Carlo Erba Instr., Italy). The aqueous solution of phenol $(\mathrm{pH}$ 2.0, $25^{\circ} \mathrm{C}$ ) of constant concentration $c_{0}$ was pumped through the column $(70 \mathrm{~mm} \times 2 \mathrm{~mm}$ i.d.) packed with sorbent at the constant flow rate of $0.5-3.0 \mathrm{ml} \mathrm{min}^{-1}$. The concentration of phenol in effluent $c$ was monitored photometrically at $280 \mathrm{~nm}$, and time from the beginning of breakthrough experiment was registered for every sampling. The experiment was finished when $c$ reached $98-99 \%$ of initial concentration $c_{0}$. The incoming concentration of phenol $c_{0}$ was chosen as the highest value belonging to the linear part of adsorption isotherm to determine wide range of $c$ values with maximum accuracy.

To determine the type of mass-transfer and calculate model's parameters, a simple but rather effective graphical solution of reciprocal task was used. The experimentally obtained breakthrough data plotted in bilogarithmic scale $c / c_{0}-t$ were matched to the tabulated solution of system Eqs. (1)-(5) $u(X, T)$ build also in the same bilogarithmic scale as set of curves in coordinates $u-T$ [29]. As follows from Eqs. (8)-(10), the values of dimensional time $t$ and its dimensionless equivalent $T$ differ in bilogarithmic scale on a constant. Thus, the matching procedure consists in simple shift of breakthrough curve in parallel to time axis to find the best consistent calculated breakthrough curve. This matching yields a corresponding pairs of dimensional and dimensionless variables-sorbent bed length $l$ and its equivalent $X$, time $t$ and its equivalent $T$. The model's parameters such as liquid film coefficient $\beta$, apparent solid diffusion coefficient $D$, distribution ratio $\Gamma\left(\mathrm{ml} \mathrm{ml}^{-1}\right)$ and $K_{\mathrm{d}}\left(\mathrm{ml} \mathrm{g}^{-1}\right)$ were calculated as follows from relations Eqs. (8)-(10):

$\beta=X \frac{v}{l} ; \quad \Gamma=\beta \frac{t}{T}$

(liquid film diffusion model)

$D=\mathfrak{R}^{2} \frac{T}{t} ; \quad \Gamma=X \frac{v \mathfrak{R}^{2}}{l D} \quad$ (solid diffusion model)

$K_{\mathrm{d}}=\frac{\Gamma}{1-\varepsilon}$

The consistence among values of distribution ratio of phenol determined under batch condition 
and calculated from breakthrough data was additionally used to prove the type of mass transfer.

When the good consistence among experimentally obtained breakthrough curve and tabulated solutions of system Eqs. (1)-(5) for both type of mass transfer was observed, the type of mass transfer was determined experimentally using stop-flow technique. In such cases the breakthrough experiment was repeated twice. In the second experiment, when the concentration of phenol in effluent reached $40-60 \%$ of its initial concentration, the solution flow was stopped inside a column for a time long enough to allow smoothing concentration gradients in sorbent particles $(1-1.5 \mathrm{~h})$. After that the breakthrough experiment was continued as described above. The breakthrough data obtained in both experiments were compared, excluding from calculation the period of time during which the solution flow was stopped. The coincidence of breakthrough curves proves the absence of significant contribution of diffusion in sorbent particles.

\section{Results and discussion}

The linear range of adsorption isotherm of phenol is the most crucial point in suitability of above-mentioned models and it has to be checked out before their application to calculations. The data on the adsorption of phenol on hexadecylsilica KSK-G $\mathrm{C}_{16}$, Merrifield resin and hypercros-

Table 2

Langmuir equation parameters $(n=7 ; P=0.95)$

\begin{tabular}{llll}
\hline Sorbent & $\begin{array}{l}Q, \\
\mathrm{mg} \mathrm{g}^{-1}\end{array}$ & $\begin{array}{l}k, \\
\mu \mathrm{g} \mathrm{g}^{-1}\end{array}$ & $\begin{array}{l}K_{\mathrm{d}}=Q k, \\
\mathrm{ml} \mathrm{g}^{-1}\end{array}$ \\
\hline KSK-G C 16 & $1.4 \pm 0.1$ & $\begin{array}{l}1.57 \pm \\
0.09\end{array}$ & $2.2 \pm 0.3$ \\
& & $\begin{array}{l}1.27 \pm \\
\text { Merrifield polystyr- }\end{array}$ & $4.1 \pm 0.5 \pm 0.8$ \\
ene & & 0.09 & \\
Amberlite XAD-2 & $79 \pm 4$ & $1.65 \pm$ & $130 \pm 7$ \\
& & 0.17 & \\
Amberlite XAD-4 & $148 \pm 6$ & $1.69 \pm$ & $251 \pm 7$ \\
& & 0.13 & \\
MN-100 & $480 \pm 60$ & $1.9 \pm 0.4$ & $920 \pm 100$ \\
MN-150 & $540 \pm 40$ & $1.6 \pm 0.2$ & $850 \pm 50$ \\
Purosorb MN-200 & $202 \pm 10$ & $3.94 \pm$ & $795 \pm 32$ \\
& & 0.35 & \\
\hline
\end{tabular}

slinked polystyrenes of $\mathrm{MN}$ series were experimentally obtained and the literature data [30] were used for Amberlite XAD-2 and XAD-4 resins (Table 2). All isotherms have had a linear part (Henry's area) up to equilibrium concentration of phenol about $70 \mu \mathrm{g} \mathrm{ml}^{-1}$. The distribution ratios of phenol $K_{\mathrm{d}}\left(\mathrm{ml} \mathrm{g}^{-1}\right)$ were calculated in linear concentration range in accordance with Langmuir equation (Table 1). Finally, incoming concentration $50 \mu \mathrm{g} \mathrm{ml}^{-1}$ of phenol in water was chosen for the investigation of adsorption kinetics under dynamic conditions.

Experimental data on the adsorption of phenol on Merrifield resin and Amberlite XAD resins are corresponded to with the liquid film diffusion model (Fig. 1). In case of hexadecylsilica KSK-G $\mathrm{C}_{16}$ and hypercrosslinked polystyrenes (MN-100, $150,-200)$ the definite choice between liquid film and solid diffusion models could not be done on the base of dynamic breakthrough curves only. The absence of reasonable impact of diffusion inside particles in overall mass transfer was proved in this case by stop-flow technique (Fig. 2). The calculated parameters of phenol adsorption according to film diffusion model are presented in Table 3.

Dynamic breakthrough curves of phenol on PLPR-S 100, Amberchrom CG-161, EnviChrom $\mathrm{P}$ and LiChrolut EN were accepted from [13]. These data are also in a good agreement with liquid film diffusion model (Fig. 3). The calculated model parameters for these sorbents are given in Table 3.

Distribution ratios of phenol $K_{\mathrm{d}}$ on hypercrosslinked polystyrenes $\mathrm{MN}$ determined in batch (Table 2) are in agreement with those calculated from breakthrough data (Table 3). This fact proves adequacy of the model chosen for the adsorption of phenol. The distribution ratios of phenol calculated from dynamic breakthrough curves for PLPR-S 100, Amberchrom CG-161, EnviChrom P, LiChrolut EN and Amberlite XAD are well correlated with their adsorption capacities determined in [13,19-21]. Some disagreement in $K_{\mathrm{d}}$ values published in literature (Table 1) and calculated from breakthrough data (Table 3) could be connected with non-linear conditions of dynamic adsorption systems used by the authors of 

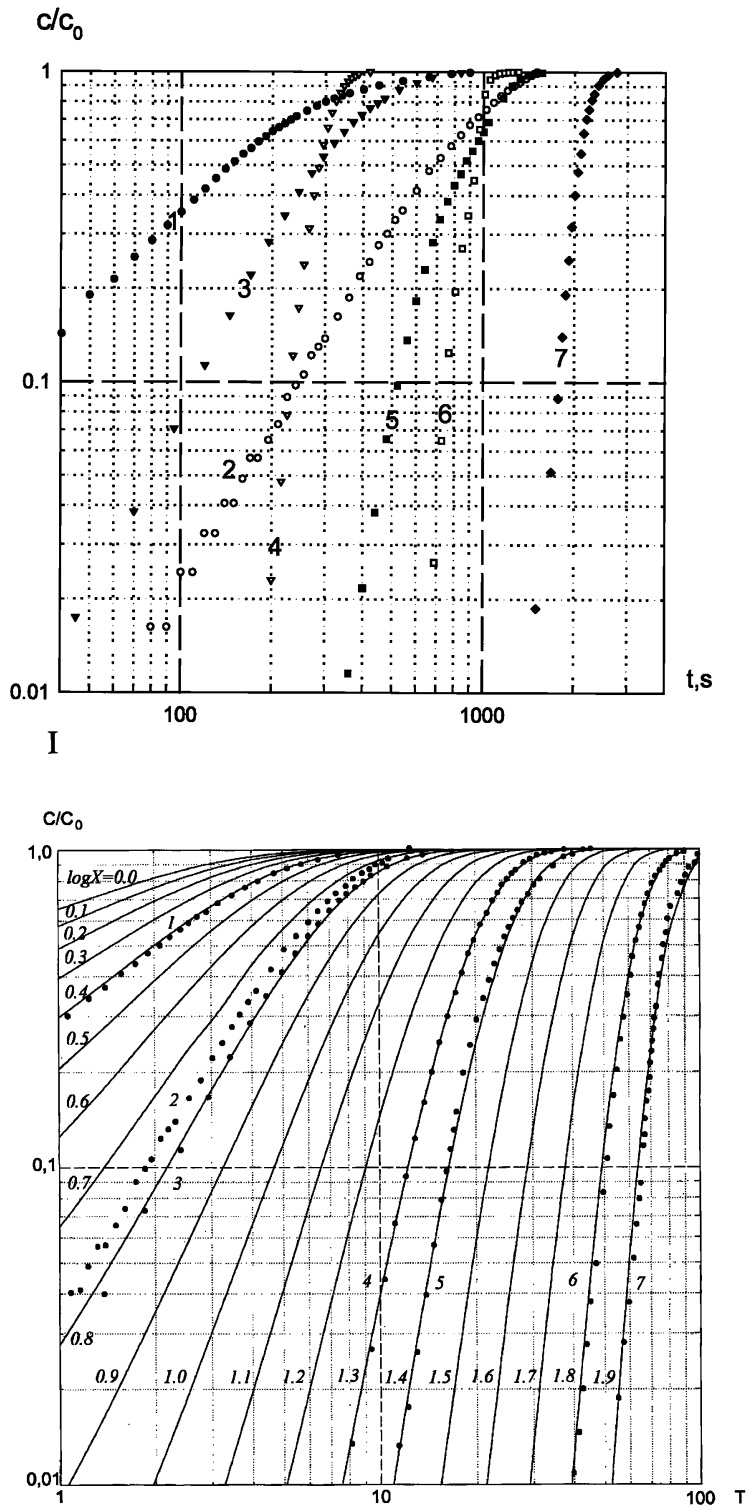

II

Fig. 1. Dynamic breakthrough curves of phenol on non-polar sorbents (experimental data). I-Experimental data: XAD-2 (1), XAD-4 (2), Merrifield-resin (3), hexadecylsilica KSK-G C 16 (4), MN-100 (5), Purosorb MN-200 (6), MN-150 (7); $v=1.5$ (1), 0.7 (2-4); 3.0 (5), 2.5 (6), 2.0 (7) $\mathrm{ml} \mathrm{min}^{-1}$; weight of sorbent: 112 (1), 132 (2), 144 (3), 141 (4), 54.1 (5), 69.8 (6), 80.7 (7) $\mathrm{mg}$; column $70 \mathrm{~mm} \times 2 \mathrm{~mm}$ i.d. II-Calculated breakthrough curves (solid lines) for liquid film diffusion model matched to the experimental data.
[13,19-21]. Nevertheless, the calculated model parameters seem to be useful for evaluation of the adsorption efficiency of different adsorbents.

In opposite to sorption in batch mode, when the process efficiency is almost completely determined by distribution ratio $K_{\mathrm{d}}$, neither this parameter, nor kinetic one (liquid film coefficient $\beta$, solid diffusion coefficient $D$ ) being considered separately can not be used as a measure of sorbent efficiency in column mode. Especially for sorption preconcentration in flow injection systems the term 'concentration efficiency, CE' was introduced by Fang [31] as 'enhancement factor of analytical signal achieved per unit of time'. In our previous work [32], this term was applied to the sorption step only as the preconcentration factor $K_{\text {conc }}$ achieved per unit of time under given value of recovery of solute $R$. Assuming nearly quantitative recovery of solute $(R \cong 1)$ among assumptions stated above and calculating preconcentration factor per volume unit of sorbent bed:

$\mathrm{CE}=K_{\text {conc }} / t=a / c_{0} t \cong w / V_{\text {bed }}=v / l$

where $w\left(\mathrm{ml} \mathrm{min}^{-1}\right)$ is flow rate and $V_{\text {bed }}(\mathrm{ml})$ is a bed volume. According to this definition, the concentration efficiency is a measure of the column productivity in dynamic preconcentration of solute.

The peculiarity of mass transfer models described above is, that when model's parameters (distribution ratio $K_{\mathrm{d}}$ and $\Gamma$, liquid film coefficient $\beta$, solid diffusion coefficient $D$, particle size $\mathfrak{R}$ ) are known and yet only preconcentration factor $K_{\text {conc }}$ and recovery of solute $R$ are given as limitative parameters, the maximum achievable in the system value of concentration efficiency $\mathrm{CE}_{\max }$ could be calculated. On our opinion, this parameter being calculated for different systems under the same values of limitative parameters $K_{\text {conc }}$ and $R$ for could be considered as the total criterion of the sorbent efficiency. A method for evaluation of $\mathrm{CE}_{\max }$ for liquid film and solid diffusion mass transfer is described below.

In dynamic preconcentration system with the conditions as stated above, at any time $\tau$ the preconcentration factor $K_{\text {conc }}(\tau)$ can be defined as: 


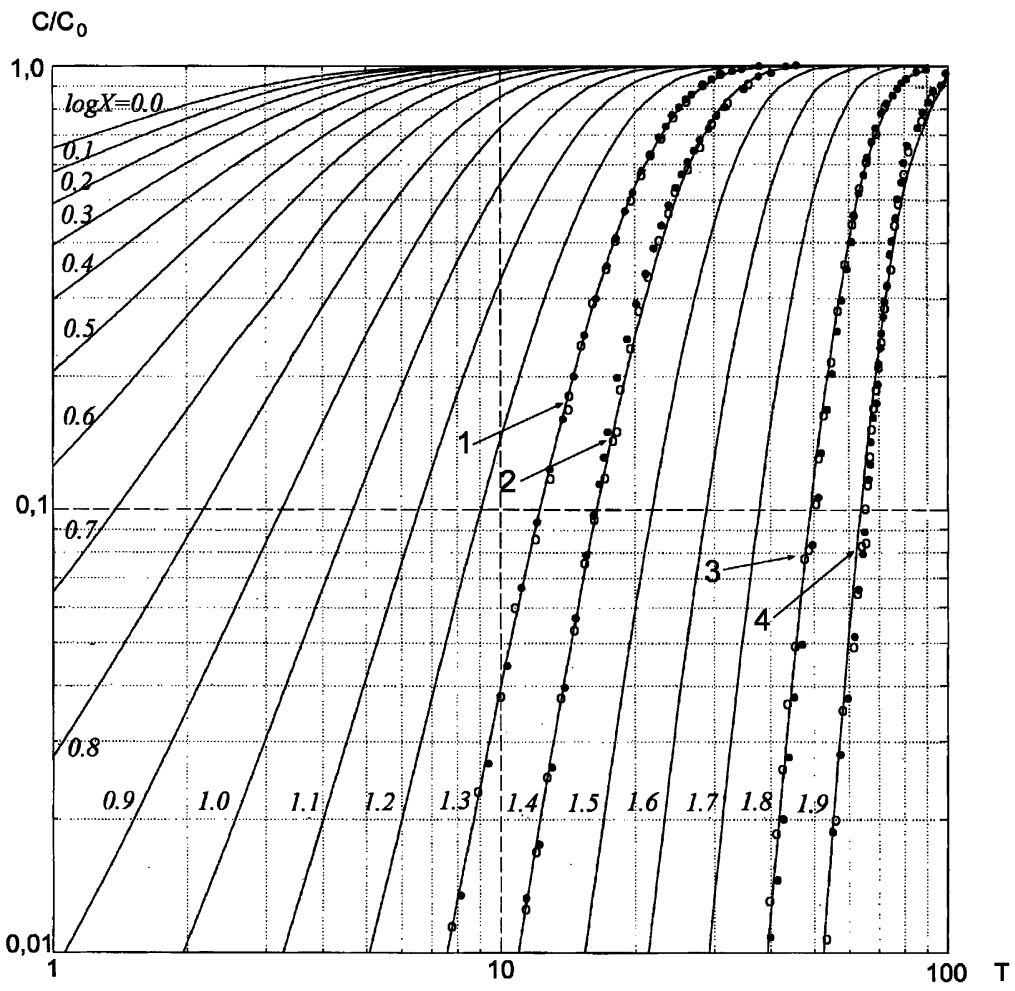

Fig. 2. Dynamic breakthrough curves of phenol obtained on non-polar sorbents in conventional mode (solid circles) and in stop-flow mode (hollow circles). Solid lines are calculated breakthrough curves for liquid film diffusion model matched to the experimental data. Sorbents and stop-flow time were: hexadecylsilica KSK-G C 16,30 min (1); MN-100, 60 min (2); Purosorb MN-200, 60 min (3), MN150, $60 \mathrm{~min}$ (4). Other experimental conditions are the same as on Fig. 1. Arrows mark the moments of stopping the flow.

$K_{\text {conc }}(\tau)=\frac{1}{c_{0} l} \int_{0}^{l} a(x, \tau) \mathrm{d} x$
As for infinite time $(\tau \rightarrow \infty) a(x, t) \rightarrow a_{0}$, the maximum preconcentration factor cannot be greater than $\Gamma$. Thus, in dynamic preconcentration

Table 3

The calculated parameters of liquid film diffusion model for the adsorption of phenol by non-polar sorbents

\begin{tabular}{|c|c|c|c|c|}
\hline Sorbent & $\mathfrak{R} \times 10^{-3}, \mathrm{~cm}$ & $\Gamma, \mathrm{ml} \mathrm{ml}^{-1}$ & $K_{\mathrm{d}}, \mathrm{ml} \mathrm{g}^{-1}$ & $\beta, \mathrm{s}^{-1}$ \\
\hline KSK-G $\mathrm{C}_{16}$ & 7.1 & $30.1 \pm 1.9$ & $47 \pm 3$ & $1.06 \pm 0.05$ \\
\hline Merrifield polystyrene & 3.0 & $20.5 \pm 1.3$ & $31 \pm 2$ & $0.37 \pm 0.02$ \\
\hline Amberlite XAD-2 & 18.9 & $24.4 \pm 2.1$ & $46 \pm 4$ & $0.39 \pm 0.02$ \\
\hline Amberlite XAD-4 & 23.9 & $39.6 \pm 0.6$ & $66 \pm 1$ & $0.31 \pm 0.01$ \\
\hline PLPR-S $100^{\mathrm{a}}$ & 1.0 & $129 \pm 6$ & $430 \pm 20$ & $19.4 \pm 0.5$ \\
\hline Amberchrom CG-161 ${ }^{\mathrm{a}}$ & 3.8 & $249 \pm 21$ & $1080 \pm 90$ & $4.7 \pm 0.5$ \\
\hline Envi-Chrom $\mathrm{P}^{\mathrm{a}}$ & 6.0 & $242 \pm 16$ & $1050 \pm 70$ & $3.6 \pm 0.2$ \\
\hline LiChrolut $\mathrm{EN}^{\mathrm{a}}$ & 4.0 & $575 \pm 37$ & $2500 \pm 160$ & $7.3 \pm 0.5$ \\
\hline $\mathrm{MN}-100$ & 3.0 & $197 \pm 2$ & $800 \pm 10$ & $5.5 \pm 0.3$ \\
\hline $\mathrm{MN}-150$ & 3.0 & $326 \pm 4$ & $880 \pm 10$ & $13.6 \pm 0.8$ \\
\hline Purosorb MN-200 & 5.0 & $250 \pm 7$ & $780 \pm 20$ & $15.5 \pm 0.2$ \\
\hline
\end{tabular}

\footnotetext{
a Calculated on the literature data [13].
} 


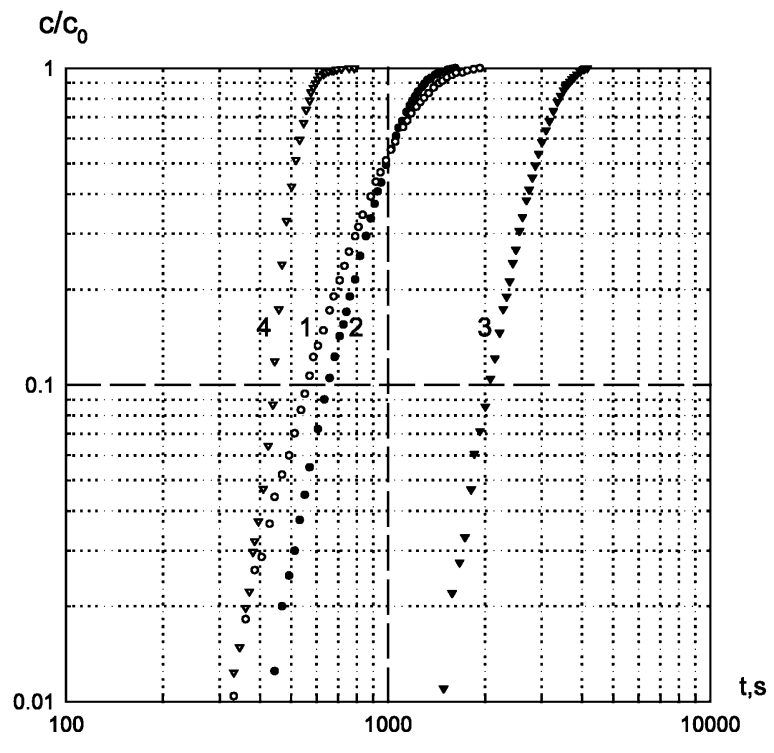

I

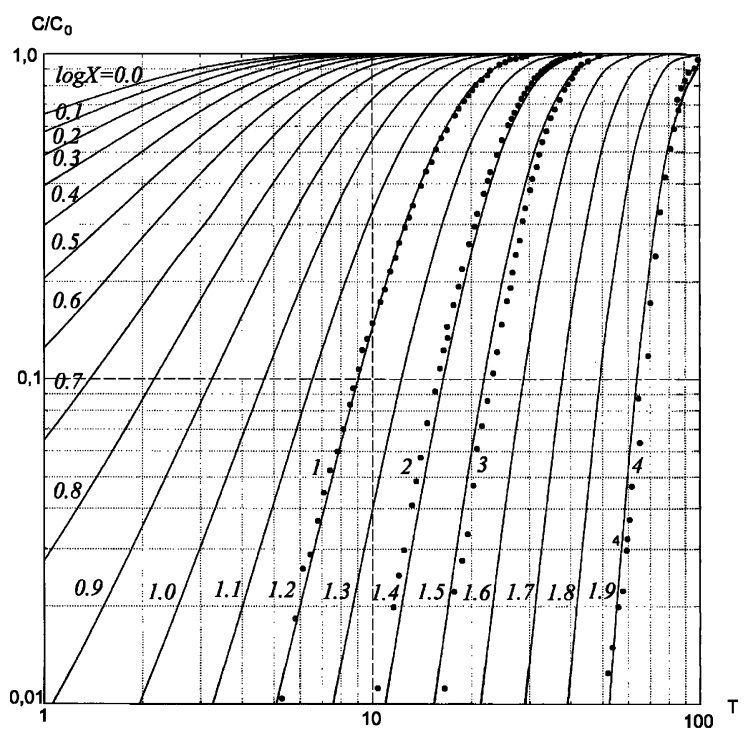

II

Fig. 3. Dynamic breakthrough curves of phenol on non-polar sorbents (according to [13]). I-Experimental data: EnviChrom P (1), Amberchrom CG-161 (2), LiChrolut EN (3),

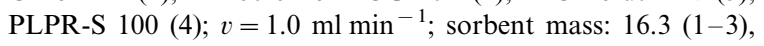
21.2 (4) $\mathrm{mg}$; column: $10 \mathrm{~mm} \times 3 \mathrm{~mm}$ i.d. II-Calculated breakthrough curves (solid lines) for liquid film diffusion model matched to the experimental data. system the preconcentration factor per unit of its maximum value $\Gamma$ (in fact, the 'expended capacity of sorbent bed') can be expressed as:

$\frac{K_{\text {conc }}(\tau)}{\Gamma}=\frac{1}{a_{0} l} \int_{0}^{l} a(x, \tau) \mathrm{d} x$

At the same time the recovery of solute $R(\tau)$ can be written as:

$$
\begin{aligned}
R(\tau) & =\frac{c_{0} w \tau-w \int_{0}^{\tau} c(l, t) \mathrm{d} t}{c_{0} w \tau} \\
& =1-\frac{1}{c_{0} \tau} \int_{0}^{\tau} c(l, t) \mathrm{d} t
\end{aligned}
$$

This gives us the 'cumulative breakthrough':

$1-R(\tau)=\frac{1}{c_{0} \tau} \int_{0}^{\tau} c(l, t) \mathrm{d} t$

As regards to solution of the system Eqs. (1)-(5) in dimensionless form, the expended capacity of sorbent bed and the cumulative breakthrough can be written in the following form:

$\eta(X, T)=\frac{K_{\text {conc }}}{\Gamma}=\frac{1}{X} \int_{0}^{X} q(X, T) \mathrm{d} X$

$\chi(X, T)=1-R=\frac{1}{T} \int_{0}^{T} u(X, T) \mathrm{d} T$

These functions were calculated according to relations Eqs. (17) and (18) from tabulated solutions of the system Eqs. (1)-(5) by numerical integration [29].

Graphical solution of the system Eqs. (17) and (18) for liquid film diffusion mass transfer is demonstrated on Fig. 4. Calculated functions $\eta(X, T)$ and $\chi(X, T)$ were plotted as a set of curves in coordinate plane $X-T$. The cross point of two curves for given values of $\eta$ (distribution ratio $\Gamma$ and preconcentration factor $K_{\text {conc }}$ ) and $\chi$ (recovery $R$ ) gives the values of dimensionless parameters $X_{\max }$ and $T_{\max }$. The concentration efficiency $\mathrm{CE}_{\max }$ and corresponding dimensional 


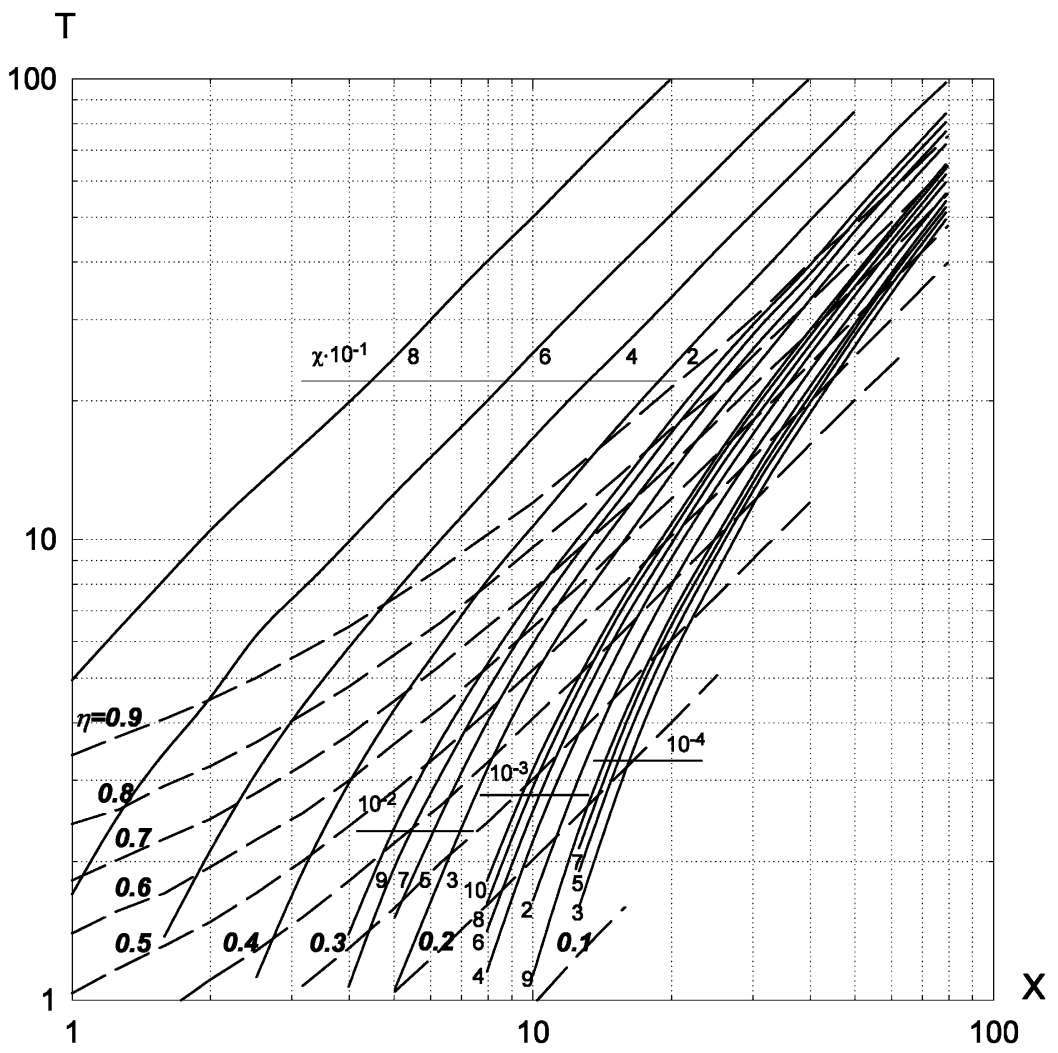

Fig. 4. Graphical evaluation of the maximum achievable preconcentration efficiency $\mathrm{CE}_{\max }$ for liquid film diffusion model. The cross point of curves representing the calculated parameters $\eta$ (dashed lines) and $\chi$ (solid lines) gives the values of dimensionless bed length $X_{\max }$ and time $T_{\max }$ for given preconcentration factor $K_{\text {conc }}$, distribution ratio $\left(K_{\mathrm{d}}, \Gamma\right)$ and recovery of solute $R$.

sorption time $t_{\max }$ are calculated from relations Eq. (9):

$\mathrm{CE}_{\max }=\frac{\beta}{X_{\max }} ; \quad t_{\max }=\frac{T_{\max } \Gamma}{\beta}$

(liquid diffusion model)

$\mathrm{CE}_{\max }=\frac{D \Gamma}{X_{\max } \mathfrak{R}^{2}} ; \quad t_{\max }=\frac{T_{\max } \mathfrak{R}^{2}}{D}$

(solid diffusion model)

It should be noted that this method allows the extremely useful tool for comparison of efficiency for various dynamic adsorption systems under different but optimum in each case conditions. If calculated $\mathrm{CE}_{\max }$ could not be achieved on some reasons (for instance on poor hydrodynamics), this parameter can still be useful for characterization of system stability. This stability allows perform- ing successful preconcentration of solute from solutions of complex composition, where the distribution ratio of solute could be much lower than in model solutions.

To compare the efficiency of sorbents under scope of present work for preconcentration of phenol, the values of $\mathrm{CE}_{\max }$ and corresponding sorption time $t_{\max }$ were calculated according to proposed method. The values of preconcentration factors $K_{\text {conc }}$ of 10 and 100 and the recovery of phenol $R=95 \%$ were chosen as limitative parameters. The corresponding values of $\eta$ and $\chi$ were obtained for each system from relations Eqs. (10), (17) and (18) using determined distribution ratios of phenol and information about bed density. Then dimensionless parameters $X_{\max }$ and $T_{\max }$ were calculated by numerical solution of the system Eqs. (17) and (18) and finally, the values 
of $\mathrm{CE}_{\max }$ and $t_{\max }$ were obtained from Eq. (19). For some sorbents and preconcentration factor 10 the values $X_{\max }$ and $T_{\max }$ were outside of bounds used in calculations. In such a case the solution of system Eqs. (17) and (18) and the values of $\mathrm{CE}_{\max }$ and $t_{\max }$ were estimated by graphical extrapolation. The results are summarized in Table 4.

The application of models Eqs. (1)-(5) allows determining the impact of both kinetic and thermodynamic factors in total concentration efficiency. As the liquid film diffusion mass transfer is proved, the model parameters are the liquid film coefficient $\beta$ and the distribution ratio $K_{\mathrm{d}}$. The value of $\beta$ includes impacts of convection, molecular and longitudinal diffusion which dependent from the properties of liquid and solid phases, i.e. by the diffusion rate of the solute in solution, the apparent surface of liquid-solid boundary etc, and by the hydrodynamic type of the flow of mobile phase.

Distribution ratio $K_{\mathrm{d}}$ reflects the sorption thermodynamics. The results obtained show that the distribution ratios of phenol for highly and hypercrosslinked polystyreness (cross-linking degree is more than $100 \%$ ) are considerably higher than for hexadecylsilica and poly(styrene-divinylbenzene)s with low cross-linking degree $(2-16 \%)$. An intermediate $K_{\mathrm{d}}$ was observed for PLRP-S 100 having cross-linking degree equal to $60 \%$. Consequently, the change in cross-linking degree results in change of sorbate-sorbent interaction energy for polymer sorbents.

According to [33], the mechanism of adsorption of organic molecules on polymeric sorbents includes either adsorption on the surface or dissolving in a solid phase, or mixed mode. It should be noted that the relative impact of each process depends on the microstructure of polymer. An increase of cross-linking degree seems to result in slow change of retention mechanism from preferable adsorption to distribution. It leads to remarkable increase in adsorption capacity as well as in distribution ratio [34,35].

An role of porous structure of poly(styrenedivinylbenzene)s and carbon black in retention of some test compounds was studied in $[36,37]$. According to these data, the retention of hydrocarbons, alcohols and esters on polymeric sorbent with cross-linking degree $43 \%\left(S=590 \mathrm{~m}^{2} \mathrm{~g}^{-1}\right)$ is approximately in 3 times stronger than on sorbent with cross-linking degree $25 \%\left(S=183 \mathrm{~m}^{2} \mathrm{~g}^{-1}\right)$. Also, the increase in surface area of carbon black from 15 to $150 \mathrm{~m}^{2} \mathrm{~g}^{-1}$ results in 10 times increase of retention. Obviously, the retention is proportional to the value of specific surface area of sorbents. In case of hypercrosslinked polystyrenes

Table 4

Calculated maximum achievable concentration efficiency $\mathrm{CE}_{\max }$ and corresponding preconcentration time $t_{\max }$ for the phenol recovery on reversed-phase sorbents

\begin{tabular}{|c|c|c|c|c|}
\hline \multirow[t]{2}{*}{ Sorbent } & \multicolumn{2}{|l|}{$K_{\text {conc }}=10$} & \multicolumn{2}{|l|}{$K_{\mathrm{conc}}=100$} \\
\hline & $\mathrm{CE}_{\max }, \min ^{-1}$ & $t_{\max }, \min$ & $\mathrm{CE}_{\max }, \min ^{-1}$ & $t_{\max }, \min$ \\
\hline KSK-G C16 & 11.0 & 0.97 & $-^{\mathrm{a}}$ & $-{ }^{\mathrm{a}}$ \\
\hline Merrifield polystyrene & 2.7 & 4.0 & $-{ }^{\mathrm{a}}$ & $-{ }^{\mathrm{a}}$ \\
\hline Amberlite XAD-2 & 3.4 & 3.0 & $-{ }^{\mathrm{a}}$ & $-^{\mathrm{a}}$ \\
\hline Amberlite XAD-4 & 3.9 & 2.8 & $-^{\mathrm{a}}$ & $-{ }^{\mathrm{a}}$ \\
\hline PLPR-S $100^{\mathrm{b}}$ & $>300$ & $<0.04$ & 44 & 2.4 \\
\hline Amberchrom CG- $161^{\mathrm{b}}$ & $>110$ & $<0.09$ & 43 & 2.5 \\
\hline Envi-Chrom $\mathrm{P}^{\mathrm{b}}$ & $>90$ & $<0.1$ & 32 & 3.2 \\
\hline LiChrolut EN $8^{\text {b }}$ & $>180$ & $<0.08$ & 110 & 1.05 \\
\hline $\mathrm{MN}-100^{\mathrm{b}}$ & $>130$ & $<0.08$ & 38 & 2.8 \\
\hline $\mathrm{MN}-150^{\mathrm{b}}$ & $>300$ & $<0.04$ & 155 & 0.68 \\
\hline Purosorb MN-200 ${ }^{\mathrm{b}}$ & $>300$ & $<0.04$ & 140 & 0.75 \\
\hline
\end{tabular}

The recovery of phenol $95 \%$, preconcentration factors 10 and 100 .

a Preconcentration factor 100 could not be achieved.

b Values of $\mathrm{CE}_{\max }$ and $t_{\max }$ for $K_{\text {conc }}=10$ were estimated by graphical extrapolation. 
$\left(S=1500 \mathrm{~m}^{2} \mathrm{~g}^{-1}\right)$ the retention of organic molecules increased drastically (in 6-7 times) as well as adsorption capacities for these polymers. Therefore, the increase of cross-linking degree leads to the change of retention mechanism.

Poly(styrene-divinylbenzene) sorbents are found the most efficient substrates for the preconcentration of phenol from water solution by SPE. The advantage of this group of sorbents is expressed sharply for polymers with high cross-linking degree $(60 \%$ and more). The difference between values of $\mathrm{CE}_{\max }$ calculated for hypercrosslinked polystyrene and Merrifield resin of gel type is about two orders of magnitude. Preconcentration factor of 100 can not be achieved with hexadecylsilica or with poly(styrene-divinylbenzene) resins of low cross-linking degree.

\section{Conclusions}

The method based on LMSD allows to compare phenol preconcentration efficiency of different sorbents under dynamic conditions. This approach may be useful for the optimal choice of sorbent in water purification and in analytical chemistry for preconcentration of trace organic compounds by SPE. The highly crosslinked poly(styrene-divinylbenzene) and hypercrosslinked polystyrene were found the most promising for phenol preconcentration.

\section{Acknowledgements}

The authors thanks to Prof E.V. Venitsianov for the helpful discussion on LMSD.

\section{References}

[1] J.C. Hoffsommer, D.J. Glover, C.Y. Hazzard, J. Chromatogr. 195 (1980) 435.

[2] G. Marko-Varga, D. Barselo, Chromatographia 34 (1992) 146.

[3] D. Puig, D. Barselo, J. Chromatogr. A 778 (1997) 313.

[4] (a) V.V. Goncharov, V.B. Goryunova, V.M. Tul'chinskii, Zavodsk, Laboratoriya 58 (1) (1992) 10; (b) V.V. Goncharov, V.B. Goryunova, V.M. Tul'chinskii, Zavodsk, Ind. Lab. 58 (1) (1992) 15.

[5] (a) Ya.I. Korenman, R.P. Lisitskaya, Zavodsk. Laboratoriya (Diag. Mater.) 64 (6) (1998) 3;

(b) Ya.I. Korenman, R.P. Lisitskaya, Ind. Lab. (Diag. Mater.) 64 (3) (1998) 3.

[6] V. Piangerelli, F. Nerini, S. Cavalli, Annali di Chimica 83 (1993) 331.

[7] C.W. Klampfl, E. Spanos, J. Chromatogr. A 715 (1995) 213.

[8] M. Castillo, D. Puig, D. Barselo, J. Chromatogr. A 778 (1997) 301.

[9] (a) I.Yu. Andreeva, L.L. Kuvaldina, Zh. Anal. Khim. 50 (1995) 45;

(b) I.Yu. Andreeva, L.L. Kuvaldina, J. Anal. Chem. 50 (1995) 42.

[10] N. Masque, R.M. Marce, F. Borrull, J. Chromatogr. A 793 (1998) 257.

[11] N.A. Penner, P.N. Nesterenko, A.V. Khryaschevsky, T.N. Stranadko, O.A. Shpigun, Mendeleev Commun. 1 (1998) 24.

[12] P. Musmann, K. Levsen, W. Radeck, Fresen. J. Anal. Chem. 348 (1994) 654.

[13] N. Masque, R.M. Marce, F. Borrull, Trends in Anal. Chem. 17 (1998) 384.

[14] F. Mijangos, A. Navarro, J. Chem. Eng. Data 40 (1995) 875.

[15] M.-W. Jung, D.W. Lee, J.-S. Rhee, K.-J. Paeng, Anal. Sci. 12 (1996) 981.

[16] B. Gawdzik, J. Gawdzik, U. Czerwinska-Bil, J. Chromatogr. 509 (1990) 135.

[17] D.C. Kennedy, Ind. Eng. Chem. Prod. Res. Develop. 12 (1973) 56.

[18] E.H. Crook, R.P. McDonnel, J.T. McNulty, Ind. Eng. Chem. Prod. Res. Develop. 14 (1975) 113.

[19] N. Masque, M. Galia, R.M. Marce, F. Borrull, J. Chromatogr. A 771 (1997) 55.

[20] PLRP-S 100A. Polymeric Reversed Phase HPLC Columns and Media. Polymer Laboratories.

[21] O. Fiehn, M. Jekel, Anal. Chem. 68 (1996) 3083.

[22] N.A. Penner, P.N. Nesterenko, M.M. Ilyin, M.P. Tsyurupa, V.A. Davankov, Chromatogrphia 50 (1999) 611.

[23] M.P. Tsyurupa, L.A. Maslova, A.I. Andreeva, T.A. Mrachkovskaya, V.A. Davankov, React. Polym. 25 (1995) 69.

[24] Hypersol-MacronetTM, Sorbent Resins, Purolite Technical Bulletin, The Purolite Company, 1995.

[25] A.V. Khryaschevskii, M.V. Podlovchenko, P.N. Nesterenko, O.A. Shpigun, Moscow Univ. Chem. Bull. 39 (3) (1998) 196.

[26] V. Coquart, M.-C. Hennion, J. Chromatogr. A 600 (1992) 195.

[27] A. Anzelius, Z. Angew. Math. Mech. 6 (1926) 291.

[28] J.B. Rosen, J. Chem. Phys. 20 (3) (1952) 387.

[29] E.V. Venitsianov, R.N. Rubinshtein, Dinamika sorbcii iz zhidkih sred (Dynamics of Sorption from Liquid Media), Nauka, Moscow, 1983. 
[30] F. Mijangos, A. Navarro, J. Chem. Eng. Data 40 (1995) 875.

[31] Zh. Fang, Flow Injection Atomic Absorption Spectrometry, Wiley, New York, 1995.

[32] E.V. Venitsianov, I.A. Kovalev, G.I. Tsysin, Teoriya i praktika sorbcionnyh processov (Theory and Practice of Sorption Processes), vol. 23, Voronezh, 1998, p. 24.

[33] A.V. Kiselev, Ya.I. Yashin, Gas-Adsorption Chromatography, Plenum Press, New York, 1969.

[34] B. Versino, F. Geiss, Chromatographia 2 (1969) 354.

[35] J.F. Johnson, E.M. Barrall, J. Chromatogr. 31 (1967) 547.
[36] (a) L.D. Belyakova, A.M. Voloschuk, L.M. Vorobjeva, O.A. Larionova, O.G. Larionov, Zh. Phys. Khimii. 69 (1995) 501;

(b) L.D. Belyakova, A.M. Voloschuk, L.M. Vorobjeva, O.A. Larionova, O.G. Larionov, J. Phys. Chem. 69 (1995) 455.

[37] (a) L.D. Belyakova, O.V. Vasilevskaya, M.P. Tsyurupa, V.A. Davankov, Zh. Phys. Khimii. 70 (1996) 1476 ;

(b) L.D. Belyakova, O.V. Vasilevskaya, M.P. Tsyurupa, V.A. Davankov, J. Phys. Chem. 70 (1996) 1374. 